\title{
I saw this somewhere else: The Spanish Ambiguous Words (SAW) database
}

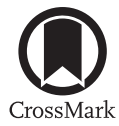

\author{
Isabel Fraga ${ }^{\mathrm{a},{ }^{*}}$, Isabel Padrón ${ }^{\mathrm{a}}$, Manuel Perea ${ }^{\mathrm{b}}$, Montserrat Comesaña ${ }^{\mathrm{c}}$ \\ ${ }^{a}$ Cognitive Processes \& Behavior Research Group, Department of Social Psychology, Basic Psychology and Methodology, \\ Faculty of Psychology, Universidade de Santiago de Compostela, Spain \\ ${ }^{\mathrm{b}}$ Departamento de Metodología and ERI-Lectura, Universitat de València, Spain \\ ${ }^{\mathrm{c}}$ Human Cognition Lab, CIPsi, School of Psychology, University of Minho, Braga, Portugal
}

Received 10 February 2016; received in revised form 5 July 2016; accepted 6 July 2016

Available online 29 July 2016

\begin{abstract}
The present paper describes the Spanish Ambiguous Words (SAW) database, which comprises 210 words (133 polysemous and 77 homographs). Three-hundred and fifteen Spanish university students took part in the study on which SAW is based. First, subjective word meanings and senses were collected by means of a meaning retrieval task. Two judges then assigned participants' responses to different categories of meaning according to lexicographical and statistical criteria. Results showed that, while there was a relatively high relationship between the number of senses included in the dictionary and those provided by participants $(r=.62)$, regression analyses on lexical decision and naming times revealed that participants' number of senses had significant predictive power, whereas those from the dictionary did not. This indicates that normative data from participants seem to better reflect the psychological reality of word senses. Hence, the SAW database constitutes a useful tool for future research into ambiguous word learning and recognition in Spanish.
\end{abstract} (C) 2016 Elsevier B.V. All rights reserved.

Keywords: Semantic ambiguity; Homographs; Polysemous words; Spanish

\section{Introduction}

Knowledge of word meanings, and the ability to share them, is central to verbal communication. The process of acquiring meanings and storing semantic representations is among the most challenging phenomena for researchers in the field of word learning and memory. Meaning is a dynamic phenomenon, both in its social and psychological dimensions. Indeed, the very experience of being a language user serves to shape semantic representations (Degani, 2011), with the mental lexicon constantly evolving. Moreover, in every language many words are semantically ambiguous and have multiple meanings, these taking on different degrees of variation throughout the life of an individual speaker.

In psycholinguistics, the concept of lexical ambiguity has sometimes encompassed both homonymous and polysemous words (e.g., Hino and Lupker, 1996), but more often refers exclusively to the former. However, in recent years many authors have come to believe that ambiguity is not a single phenomenon. Words that have multiple meanings or senses are generally classified into two types: homonymous and polysemous words, and as will be shown below, these

\footnotetext{
The handling Editor for this article was Harry Whitaker.

* Corresponding author at: Dpto. de Psicoloxía Social, Básica e Metodoloxía, Facultade de Psicoloxía-Universidade de Santiago, Rúa Xosé María Suárez Núñez s/n. Campus sur, 15782 Santiago de Compostela, Spain. Tel.: +34 881813787.

E-mail address: isabel.fraga@usc.es (I. Fraga).
} 
two types of words have not only been demonstrated to be psychologically real but also "to behave" differently (Klepousniotou, 2002; Klepousniotou and Baum, 2007).

From a lexicographical perspective, homonymy entails a lexical unit whose different meanings have different etymological origins, this reflected in two or more entries in a dictionary. That is, homonymous words are different in fact words that are written (homographs) and/or pronounced (homophones) in the same way, yet have differing meanings. For example, bat can refer to an animal or to an implement used in sports such as baseball. It is also assumed that the multiple meanings of homonymous words (i.e., those corresponding to different entries in the dictionary) are unrelated meanings. Also, in many cases one of the meanings of the homograph, the 'dominant meaning', is much more frequent than the other (s), these latter called the subordinate meanings. Conversely, in polysemy, a single lexical item (i.e. with only one entry in the dictionary) represents a unique word with several different but related senses (Lyons, 1977). For example, needle can refer to a sewing needle, a hypodermic needle, the stylus of a record player, etc.

The recognition of ambiguous words has been investigated widely in English, typically using healthy, clinical experimental participants (e.g., Duffy et al., 1988; Milberg et al., 1987; Sereno et al., 2003), thanks in part to the numerous normative studies that have been developed over the past four decades. Such studies have used a variety of procedures to collect multiple meanings of words, including participants being asked to write down the first word that comes into their heads, i.e., association tasks (e.g., Gawlick-Grendell and Woltz, 1994; Nelson et al., 1980), or asking them to provide an unlimited number of meanings (e.g., Geis and Winograd, 1974). Procedures like these have been used extensively since Rubenstein et al. (1970) classic study (in which faster response times (RTs) were found for homographs than for unambiguous words), although since they often take into account only a few meanings, such studies tend to underestimate the subordinate meanings of words and their relatedness. On the other hand, in studies where participants are given the opportunity to provide all the meanings they know, their responses often show some degree of semantic overlap (i.e., relatedness), perhaps reflecting an overlap of semantic representations in the lexicon. Thus, relatedness is a crucial variable for research on semantic organization and processing (Azuma, 1996; Moldovan et al., 2014), although it is difficult to group or indeed to separate meanings based on the responses provided by different individuals. For this reason, having collected subjective meanings, researchers frequently use a dictionary to determine whether or not different meanings fall in the same meaning categories. In turn, dictionaries often include words meanings or senses that average speakers are not familiar with, and such meanings tend not to be retrieved fully, if at all; that is, the corresponding semantic representations are either rarely activated or simply absent. Thus, some lexicographical criteria can be considered psychologically irrelevant and therefore inadequate for the grouping of meanings (Gernsbacher, 1984). In order to overcome these limitations, Gee and Harris (2010) used a procedure in which participants were asked to classify associates into one, two, or more of the multiple meanings of a set of homographs, these selected from previously published norms (Experiment 1). However, the final meaning categories were also established according to a dictionary and following the criteria of the experimenters. Importantly, when the authors asked a new sample of participants to provide only two meanings for each homograph (Experiment 4), the total number of meanings generated was not significantly different from the one generated through the first procedure. It seems, then, that the controversial distinction between dictionary and subjective meanings no longer has any real bearing for research into ambiguity processing. As Armstrong et al. (2012) have argued, "dictionary definitions are relatively successful at exhaustively capturing the meanings of most words" (p. 1020). What we should keep in mind is the fact that lexicographers and psycholinguists typically have different goals. While the former aim to compile all the meanings and senses of words, psycholinguists are interested in the mental lexicon and how it is organized and accessed. Nonetheless, it should be noted that, in collecting the meanings of the words, lexicographers also take into account their frequency of use, and that they work within a framework in which both they and other language users are understood to have mental lexicons. It is, then, of interest to verify the extent to which dictionary and subjective meanings concur and correlate.

In Spanish, empirical research on the recognition and processing of ambiguous words has been somewhat scarce (Cuetos et al., 1997; Ferrándiz and Peraita, 1985; Nievas et al., 2005). The words selected in these experiments were taken from normative studies (polysemy: Domínguez et al., 2001; homonymy and polysemy: Estévez, 1991; associates for a list of homographs: Nievas and Cañas, 1993). More recently, Gómez-Veiga et al. (2010) published a list of 113 ambiguous words, which included data on both adults and children. Although interesting and useful, none of these databases makes a systematic cross-validation between the dictionary and the participants' meanings. Furthermore, they do not take into account the differentiation between 'meanings' and 'senses', which is directly related to the homonymy/ polysemy distinction, and which has been shown to be fundamental for lexical access (see Rodd et al., 2002).

As noted above, the distinction between homonymy and polysemy is relative in psychological terms, and the idea of a continuum between the two extremes seems more appropriate. Even so, it has been established that the type of ambiguity does involve representation and processing differences. Thus, whereas homonymy seems to hinder word recognition (e. g., Klepousniotou and Baum, 2007; but see Armstrong et al., 2012), polysemy tends to facilitate it, when ambiguous words are compared with unambiguous words presented in isolation, in both lexical decision and naming (the so-called ambiguity advantage; e.g., Azuma and Van Orden, 1997; Cuetos et al., 1997; Frazier and Rayner, 1990; Klepousniotou, 
2002; Klepousniotou and Baum, 2007; Pexman and Lupker, 1999; Rubenstein et al., 1970; see also Hino et al., 2006 for a review of ambiguity effects in lexical decision and semantic tasks). These findings have also been confirmed in eye movement experiments (e.g., Frazier and Rayner, 1990) and EEG studies (e.g., Klepousniotou et al., 2012), and are usually explained in terms of different representations for each meaning, in the case of homonymous words, and a single mental representation, for polysemous words. According to Klepousniotou (2002), homonymy relies on a process of 'sense selection', while polysemy relies on a process of 'sense creation'. In a similar vein, Rodd et al. (2002) proposed that, for the ambiguity advantage with isolated words, the critical distinction might be between meanings and senses rather than between ambiguous and unambiguous words. Indeed, these authors found a facilitation effect of the number of senses (NoS): ambiguous words with many senses provoked faster responses in both visual and auditory lexical decision tasks than words with few senses. Conversely, a disadvantage effect has been reported in ambiguous words with unrelated multiple meanings when compared with unambiguous words (see also Klepousniotou and Baum, 2007). Rodd et al. (2002) showed that this disadvantage ambiguity effect was in turn modulated by meaning relatedness (but see Hino et al., 2006), a variable that tends to interact with the NoS (Azuma and Van Orden, 1997). Thus, as Rodd et al. (2002) suggested, words considered as ambiguous between meanings in previous studies may in fact have been ambiguous between senses. There is also recent evidence for differential processing in two categories within polysemy, namely regular and irregular (Rabagliati and Snedeker, 2013). These and other findings (e.g., Hino et al., 2006) have notable consequences for models of word recognition (Rodd et al., 2004), and underline the need for normative studies of ambiguous words that, like dictionaries, should distinguish between the number of meanings (NoM) and the NoS.

Finally, recent electrophysiological evidence has also shown differences between homonymous and polysemous words in the N400 component as a function of meaning dominance (Klepousniotou et al., 2012), a measure which has typically been limited to reporting meaning frequency for homographs (e.g., Gawlick-Grendell and Woltz, 1994; Gee and Harris, 2010; but see also Estévez [1991,Study 2] for an exception in a Spanish database). Thus, regardless of whether they are homonymous or polysemous words, normative studies should include estimates of meaning dominance for all kinds of lexical items. Furthermore, as Gee and Harris (2010) pointed out, many ambiguous words have more than two meanings, and it is crucial that they all be reported. It is indeed intriguing to see how novel, less frequent (i.e., subordinate) meanings (and senses) are learned and incorporated into those semantic representations previously stored in the lexicon. Rabagliati and Snedeker (2013) claimed that "developmental accounts of the lexicon need to explain how children learn individual senses while also constructing core meanings" (p. 1359).

The main aim of the present study was to gather all meanings reported by speakers for a set of 210 Spanish words using a meaning retrieval task, with subsequent dictionary validation. Hitherto most studies focused on meaning (or sense) relatedness have only looked at homonymous or polysemous words. The norms used here include both kinds of terms, and contain virtually all existing homographs (nouns) in Spanish. With regard to homonymous words, although most Spanish homographs are homophones due to the orthographic transparency of the language, there are also a number of homophones which are not homographs (for example, vello [hair] and bello [beautiful]). These have not been included in the database. Henceforth, we will use the terms "homonymous" and "homograph(s)" interchangeably. In the study, the selection of words was made using the Spanish Dictionary published by the Real Academia Española (RAE; Spanish Royal Academy $(2001,22 n d$ version) as well as previous Spanish databases; meanings freely retrieved from participants were then collected; finally, the different senses for each word were determined based on statistical and lexicographical criteria. So, words in the database were classified according to the lexicographical criterion of ambiguity (homonymy/polysemy), as well as to the NoS provided by participants. The different subjective meanings and senses associated with those words are also included.

\section{Method}

\subsection{Participants}

A total of 315 native Spanish speakers ( $M_{\text {age }}=21.97 ; S D=3.98$ years; 263 females) participated as volunteers in the study. All were graduates or undergraduates and had normal or corrected to normal vision. The majority were students at the University of Santiago de Compostela, but there were also some students from other Spanish universities.

\subsection{Materials}

First, we collected all the homonymous and polysemous words of seven letters or less from previously published Spanish databases (Domínguez et al., 2001; Estévez, 1991; Nievas and Cañas, 1993). After discarding repetitions, we added five new words: bota [boot, bounce, launch], caballo [horse, knight, heroin], cadena [chain, string, sound system], foco [spotlight, focus], and puro [pure, cigar]. Although the main meanings of most words corresponded to nouns $(91 \%$ of 
the cases), a small percentage included meanings from other word classes (e.g., puro can be an adjective [pure] or a noun [cigar]; sierra, can be a noun [range, saw] or a verb [he/she/it saw \{3rd person singular of verb "to saw" in the present indicative\}]). We then looked up all the words in the RAE dictionary. In each case, the number of entries, as well as the number of senses (NoS), were counted; meanings which were regionally specific (either within Spain or in Latin American) or which were in disuse were discarded. A small set of words that only had one entry with one sense in the RAE dictionary were also discarded: (choza [hut], desván [attic], folleto [brochure], lupa [magnifying glass], marido [husband], nuca [nape], peseta [peseta], ropa [clothes], rosal [rose bush], and vega [meadow]); note that these excluded words also have only one meaning in both Estévez (1991) and Domínguez et al. (2001) databases. Finally, we selected all remaining words with two or more entries in the dictionary but which had not been included in the previous databases. In total some 333 Spanish words were gathered: 256 of these were polysemous (i.e., they had one entry with several senses in the dictionary) and 77 were homographs (i.e., they had two or more entries in the dictionary). ${ }^{1}$ Thirty-four of the homographs had 8 or more senses, whereas the remaining 43 words had 7 or fewer senses (for homographs the total NoS in the dictionary was computed by adding the NoS of all their lexical entries; see Section 3). We selected a final pool of 133 polysemous words based on their lower frequency in the Spanish EsPal database (Duchon et al., 2013); note that the lower the frequency, the higher the facilitation effects of polysemy on visual-word recognition (Cuetos et al., 1997; Jastrzembski, 1981). Thus, the final set included 210 words: 34 homographs with 8 senses or more $(\mathrm{H}+;$ mean NoS $=12.32$, mean frequency $=72.5)$, 43 homographs with 7 senses or less $(\mathrm{H}-;$ mean NoS $=4.88$, mean frequency $=60.0), 59$ polysemous words with 8 senses or more $(P+;$ mean NoS $=12.12$, mean frequency $=70.6)$, and 74 polysemous words with 7 senses or less $\left(P_{-} ;\right.$mean NoS $=4.74$, mean frequency $\left.=56.1\right)$.

\subsection{Procedure}

The words were proportionally distributed in seven lists of 30 words each. Three orders for each list were created randomly, resulting in 21 different booklets. Each booklet included a first page with the instructions, in which participants were asked to write down every word meaning directly, and in case of difficulties were given the option of writing a sentence with that word in it, as an alternative means of indicating the meaning. They were then presented with two words - one homonymous and one polysemous word - that served as examples, followed by different meanings and senses, plus some sentences with the word embedded in them (for example, the homonymous word "caballo" [horse, heroin, knight, neck pain..] was followed by: animal [animal], droga [drug], pieza de ajedrez [knight], and "No puedo girar la cabeza porque tengo un caballo".. [I can't turn my head because I have a "caballo"]). In the remaining pages, words appeared on the left hand side of the page followed by a wide blank space in which participants were asked to write all the word meanings they recalled. All pages included four words, except the final one, which included two words. Fifteen participants completed each booklet; thus, 45 participants responded to each word list (i.e., to each word). The whole task, performed collectively, lasted around $1 \mathrm{~h}$.

\subsection{Response categorization}

Most participants used separate lines to write down each distinct sense, and a few people used commas or semicolons to separate them. Sometimes, they added information between brackets next to the sense to further specify what they meant. The total number of responses left blank was less than $1 \%$. Participants' responses were assigned to meaning categories following three steps. First, two judges (one of which was one of the authors) computed every meaning given by each participant, and together decided whether to generate a new meaning or assign it to a previously established one. At the end of this stage, some words and their meanings were reviewed to adjust decisions made at the beginning of the process (when only a few participants' responses had been rated) and to refine the general criterion. This was an "opencriterion phase", since when in doubt a particular sense was maintained rather than subsumed into another category. Two of the authors (one of those from the first stage) then evaluated all meanings for each word again, according to statistical and dictionary criteria. Responses that conveyed meanings either related to the same referent or with the same function, and which corresponded to a unique sense in the dictionary, were collapsed. Likewise, if two meanings corresponding to only one sense in the dictionary were very frequent but were given by less than $10 \%$ of the participants, they were subsumed. Moreover, unless expressed by more than $10 \%$ of participants, the following meanings were removed: (1) unknown meanings which did not appear in the dictionary; (2) meanings assignable to several different categories when it was impossible to discern which of the categories should be assigned; (3) surnames and personal or commercial names. In the case of meanings corresponding to both a noun and a verb (20\%), if more than $10 \%$ of participants gave different

\footnotetext{
${ }^{1}$ This confirms the fact that multiple senses are considerably more frequent in language than multiple unrelated meanings (Rodd et al., 2002).
} 
responses for an instrument and the corresponding action, both senses were considered (see the word sierra [saw] for an example). In addition, those meanings not included in the dictionary which were provided by less than $10 \%$ of the participants, but which were easily understood by the two judges, were preserved as idiosyncratic responses. Finally, localisms and illegible responses were considered invalid. Despite this well-controlled process, the categorization of a few senses remained difficult. For instance, aside from other meanings, many participants responded to the word máscara [mask] as carnaval [carnival], which might refer to sense of careta [mask] or disfraz [fancy dress]. We decided to maintain all such associates given by more than $10 \%$ of participants even when they had also responded with another tightly related sense.

\section{Results and discussion}

In this section, we describe the database, then examine the covariation in the number of senses given by participants (PNoS) and in the dictionary (DNoS). We then present a validation study to test the predictive power of PNoS and DNoS on lexical decision and naming response times. Finally, we contrast some relevant aspects of previous Spanish databases and the one described here.

\subsection{Dictionary and subjective meanings and senses for 210 Spanish words: The SAW database}

All data were recorded in an Excel file containing four sheets, one for each set of words $(\mathrm{H}+, \mathrm{H}-, \mathrm{P}+, \mathrm{P}-)$. Every sheet presents the words (in rows) in alphabetical order with the following labels (in columns):

- Code, in which the first and second digits refer to ambiguity $(1=$ homographs, $2=$ polysemous $)$ and NoS $(1=$ many, $2=$ few), respectively, and the third and fourth digits correspond to the word order on the sheet (e.g., the numerical code 2101 refers to a polysemous word with many senses, which is the first one in its category);

- Word: the word. In some cases the word is followed by an asterisk (see below);

- NoL: the number of letters;

- LogFreq (log Frequency per million) taken from the EsPal subtitles database (Duchon et al., 2013);

- NoE: the number of entries (i.e., unrelated meanings) in the dictionary. All homonymous words in the $\mathrm{H}+$ set have either two or three entries. As regards the $\mathrm{H}$ - set, most of the words have two entries, two words have 3 entries, and only one has four (solar [lineage and site, sun, pave, sole]);

- NoS-E1... NoS-E4: the number of senses in the 1st, 2nd. . . 4th dictionary entries (these columns are only included in the sheets of homonymous words);

- DNoS: the total number of senses in the dictionary, i.e., for homonymous words, the sum of the previous columns. Assigning the words to the "many senses" and the "few senses" sets (sheets) was based on this value;

- Senses: the different senses given by participants (in words or definitions);

- PNoS: the total number of participants' senses (i.e., the number of rows in the previous column). Note that in some cases a word included on a specific sheet can have a value in the PNoS cell which does not match the DNoS. Thus, for example, a word like agente [police officer, insurance agent..], which was assigned to the P- set (since it has six senses in the dictionary), has more than eight senses according to the participants. These words are marked with an asterisk (*);

- Freq Sense: the percentage of participants who responded by giving that sense;

- DoB: the degree of balance between the primary and the secondary meaning of the word, in qualitative terms (balanced, unbalanced, highly unbalanced ${ }^{2}$ ). Table 1 shows several examples in each set along with their primary and secondary meanings, as well as their corresponding DoBs;

- FrO1... FrO6: the percentage of participants who gave that sense as their 1st. . .6th response;

- MeanOrder: the average order in which each sense was given.

As examples, the normative values for five words are presented in Fig. 1. The complete dataset can be given as an Excel file in the supplementary material.

\footnotetext{
${ }^{2}$ This value was computed according to Estévez's (1991) procedure, who calculated the degree of balance between the first two meanings by subtracting the proportion of participants who gave the secondary meaning from those who gave the primary one. The higher the value, the higher the dominance of the primary meaning over the secondary one, in such a way that a value of 20 and below is considered to represent two balanced meanings, a value between 21 and 50 represents unbalanced meanings, and a value above 50 represents highly unbalanced meanings. Although the DoB is generally associated with homonymous words, in previous Spanish databases it has also been calculated for polysemous words (e.g., Domínguez et al., 2001; Estévez, 1991). Therefore, we provide it for all words in the database.
} 
Table 1

Examples in each set of words $\left(\mathrm{H}+, \mathrm{H}_{-}, \mathrm{P}+\right.$ and $\mathrm{P}-$ ) with their primary and secondary meanings (senses) and their corresponding DoB

\begin{tabular}{|c|c|c|c|}
\hline Set & Word & Primary and secondary meanings (senses) & DoB \\
\hline \multirow[t]{3}{*}{$\mathrm{H}+$} & DAMA & $\begin{array}{l}\text { P- señora [lady, dame] } \\
\text { S- ficha de juego de damas [(chess) queen] }\end{array}$ & $B(12)$ \\
\hline & BANDA & $\begin{array}{l}\text { P- de música [band, group] } \\
\text { S- honorifica [wide ribbon worn across chest, sash] }\end{array}$ & $U(31)$ \\
\hline & COLONIA & $\begin{array}{l}\text { P- fragancia [cologne] } \\
\text { S- de personas asentadas en un lugar [community] }\end{array}$ & $\mathrm{HU}(58)$ \\
\hline \multirow[t]{3}{*}{$\mathrm{H}-$} & CORTEZA & $\begin{array}{l}\text { P- de los árboles [tree, bark] } \\
\text { S- corteza terrestre [(geology) crust] }\end{array}$ & $\mathrm{B}(1)$ \\
\hline & CORAL & $\begin{array}{l}\text { P- arrecife de coral [choral] } \\
\text { S- relativo al coro [choir] }\end{array}$ & U (42) \\
\hline & BORDE & $\begin{array}{l}\text { P- persona desagradable [churl] } \\
\text { S- límite (genérico) [border, edge] }\end{array}$ & $\mathrm{HU}(52)$ \\
\hline \multirow[t]{3}{*}{$\mathrm{P}+$} & BANCO & $\begin{array}{l}\text { P- para sentarse [bench] } \\
\text { S- entidad bancaria [bank] }\end{array}$ & $B(5)$ \\
\hline & CULTO & $\begin{array}{l}\mathrm{P} \text { - de nivel cultural alto [cultured, learned] } \\
\mathrm{S} \text { - acto de veneración u homenaje (genérico) [worship] }\end{array}$ & $\cup(44)$ \\
\hline & ANILLO & $\begin{array}{l}\text { P- joya, sortija [ring, earring] } \\
\text { S- arandela, aro [hoop, washer] }\end{array}$ & $\mathrm{HU}(62)$ \\
\hline \multirow[t]{3}{*}{$\mathrm{P}-$} & BESTIA & $\begin{array}{l}\text { P- animal fiero, salvaje [beast] } \\
\text { S- insulto (bruto, ignorante) [thug, oaf] }\end{array}$ & $B(2)$ \\
\hline & CÁNCER & $\begin{array}{l}\text { P- enfermedad [cancer] } \\
\text { S- signo del zodíaco [(Zodiac) Cancer] }\end{array}$ & $U(23)$ \\
\hline & AGENTE & $\begin{array}{l}\text { P- de policía, de tráfico [(police, traffic) officer] } \\
\text { S- de seguros, mediador [insurance agent, mediator] }\end{array}$ & $\mathrm{HU}(60)$ \\
\hline
\end{tabular}

\begin{tabular}{|c|c|c|c|c|c|c|c|c|c|c|c|c|c|c|c|c|}
\hline \multicolumn{17}{|c|}{ The Spanish Ambiguous Words (SAW) database } \\
\hline CODE & WORD & NoL & LogFreq & NoE & DNoS & SENSES & PNoS & Freq Sense & DoB & Fr01 & FrO2 & FrO3 & FrO4 & FrO5 & FrO6 & Mean Order \\
\hline 2201 & ABANICO & 7 & 0,40 & 1 & 7 & & 5 & & & & & & & & & \\
\hline & & & & & & utensilio para darse aire & & 95 & \multirow{5}{*}{ B } & 64 & 31 & 0 & 0 & 0 & 0 & 1,33 \\
\hline & & & & & & gran cantidad, variedad de posibilidades & & 75 & & 20 & 44 & 11 & 0 & 0 & 0 & 1,88 \\
\hline & & & & & & de colores & & 21 & & 13 & 4 & 4 & 0 & 0 & 0 & 1,60 \\
\hline & & & & & & acción de abanicar & & 11 & & 2 & 0 & 9 & 0 & 0 & 0 & 2,60 \\
\hline & & & & & & ciclismo & & 4 & & & & & & & & \\
\hline \multirow[t]{7}{*}{2202} & ACIDO & 5 & 1,06 & 1 & 4 & & 6 & & & & & & & & & \\
\hline & & & & & & sabor & & 88 & \multirow{3}{*}{ B } & 53 & 31 & 4 & 0 & 0 & 0 & 1,45 \\
\hline & & & & & & químico & & 87 & & 40 & 36 & 11 & 0 & 0 & 0 & 1,67 \\
\hline & & & & & & tipo de humor & & 26 & & 4 & 13 & 7 & 2 & 0 & 0 & 2,25 \\
\hline & & & & & & droga & & 7 & & & & & & & & \\
\hline & & & & & & tipo de color & & 4 & & & & & & & & \\
\hline & & & & & & ácido graso & & 2 & & & & & & & & \\
\hline \multirow[t]{14}{*}{2203} & AGENTE* & 6 & 2,20 & 1 & 6 & & 13 & & & & & & & & & \\
\hline & & & & & & de policía, de tráfico & & 86 & \multirow{2}{*}{$\mathrm{HU}$} & 53 & 24 & 7 & 2 & 0 & 0 & 1,51 \\
\hline & & & & & & de seguros, mediador & & 26 & & 4 & 13 & 9 & 0 & 0 & 0 & 2,17 \\
\hline & & & & & & agente infeccioso (patógeno) & & 22 & & 4 & 9 & 9 & 0 & 0 & 0 & 2,20 \\
\hline & & & & & & comercial, representante & & 18 & & 2 & 7 & 7 & 2 & 0 & 0 & 2,50 \\
\hline & & & & & & sujeto agente (gramática) & & 16 & & 7 & 2 & 7 & 0 & 0 & 0 & 2,00 \\
\hline & & & & & & agente inmobiliario & & 11 & & 7 & 0 & 2 & 2 & 0 & 0 & 2,00 \\
\hline & & & & & & vigilante de seguridad & & 11 & & 7 & 2 & 2 & 0 & 0 & 0 & 1,60 \\
\hline & & & & & & agente secreto & & 11 & & 2 & 9 & 0 & 0 & 0 & 0 & 1,80 \\
\hline & & & & & & agente externo, erosivo & & 11 & & 0 & 11 & 0 & 0 & 0 & 0 & 2,00 \\
\hline & & & & & & de bolsa & & 9 & & & & & & & & \\
\hline & & & & & & químico, contaminante & & 9 & & & & & & & & \\
\hline & & & & & & agente federal & & 4 & & & & & & & & \\
\hline & & & & & & agente facilitador & & 2 & & & & & & & & \\
\hline \multirow[t]{3}{*}{2204} & AJEDREZ & 7 & 1,04 & 1 & 3 & & 2 & & & & & & & & & \\
\hline & & & & & & juego de estrategia & & 98 & HU & 98 & 0 & 0 & 0 & 0 & 0 & 1,00 \\
\hline & & & & & & decoración o estampado & & 7 & & & & & & & & \\
\hline \multirow[t]{4}{*}{2205} & ÁNIMO & 5 & 1,23 & 1 & 4 & & 3 & & & & & & & & & \\
\hline & & & & & & estado de ánimo & & 98 & \multirow{3}{*}{ B } & 69 & 29 & 0 & 0 & 0 & 0 & 1,30 \\
\hline & & & & & & acción de animar, dar esperanza & & 78 & & 29 & 49 & 0 & 0 & 0 & 0 & 1,63 \\
\hline & & & & & & voluntad, intención & & 11 & & 2 & 0 & 9 & 0 & 0 & 0 & 2,60 \\
\hline
\end{tabular}

Fig. 1. Example of normative data collected for five Spanish ambiguous words: NoL, number of letters; LogFreq, log frequency per million; NoE, number of entries; DNoS, dictionary number of senses; PNoS, participants' number of senses; Freq Sense, percentage of participants who responded by giving that sense; DoB, degree of balance; B, balanced; HU, highly unbalanced; FrO1.. FrO6, percentage of participants who gave that sense as their 1st... 6th response; MeanOrder, the average order in which each sense was given. *Words with mismatched DNoS and PNoS. 


\subsection{Comparisons between dictionary (DNoS) and participants (PNoS)}

Once all data were computed and registered, we calculated the Pearson correlation between the total number of dictionary senses $(D N o S ;$ mean $=8.10 ; S D=4.54)$ and the total number of participants' senses $(P N o S ;$ mean $=7.90$; $\mathrm{SD}=4.08)(N=210)$. This index revealed a significant correlation between the two variables $(r=.62 ; p<.001)$. These results confirm that meanings and senses included in dictionary definitions (e.g., in the RAE dictionary) tend to encompass the meanings known by native speakers.

What we should also note is that more than $98 \%$ of the participants provided one, two or three meanings, and $71 \%$ of them provided up to 4 meanings, whereas only $31 \%$ and $8 \%$ provided 5 and 6 meanings, respectively. Likewise, only $15 \%$ of the words were assigned 6 senses, 33\% were given 5 senses, and $70 \%$ were given 4 senses, whereas $92 \%, 99 \%$, and $96 \%$ were responded to with at least three, two, and one sense(s), respectively. ${ }^{3}$

\subsection{Validity: Word identification times and NoS}

To validate the database, we conducted a lineal regression analysis on the word identification times taken from two recent Spanish databases (lexical decision: González-Nosti et al., 2014; naming: Davies et al., 2013). In particular, 131 of the words presented in the current database are included in these databases. In the regression analyses, response time was the dependent variable and $\log _{10}$ of word frequency, number of letters, orthographic neighborhood (as measured by OLD20 taken from EsPal; Duchon et al., 2013), and the numbers of senses generated by participants (PNoS) were used as predictors. In the lexical decision data, the regression analysis revealed facilitative effects of word-frequency $(\beta=-.29$, $t=-3.64, p<.001)$ and PNoS $(\beta=-.24, t=-2.86, p=.005)$, whereas the effect of number of letters was inhibitory $(\beta=.34, t=2.90, p=.004)$. The effect of OLD20 showed a nonsignificant facilitative trend $(\beta=-.16, t=-1.32, p=.19)$. Thus, the words from the present database show the expected facilitative effect of number of senses (PNoS) on lexical decision times.

In the naming data, the regression analysis again revealed facilitative effects of word-frequency $(\beta=-.14, t=-1.93$, $p=.056)$ and PNoS $(\beta=-.18, t=-2.35, p=.02)$, whereas the effect of number of letters was inhibitory $(\beta=.43, t=3.88$, $p<.001)$. The effect of OLD20 was not significant $(\beta=.08, t<1)$. As usual in transparent orthographies, lexico-semantic effects in the naming task (i.e., word-frequency, PNoS) were slightly weaker than in the lexical decision task, whereas sublexical effects (number of letters) were greater in naming than in lexical decision.

In sum, the regression analyses on the lexical decision and naming times with the present set of words reflect a facilitative effect of PNoS on word processing. It is worth noting here that if we had used the dictionary number of senses (DNoS) as a predictor instead of PNoS, its effect on response times in the regression analyses would have been negligible ( $\beta=-.09$ in lexical decision times; $\beta=.07$ in naming times). This dissociation reflects the fact that, while there is a relatively high relationship between DNoS and PNoS $(r=.62)$, the normative data from participants may better reflect the psychological reality of a word's senses. This divergence may parallel, to some degree, the greater explanatory power of estimates of word frequencies extracted from subtitles (i.e., an estimate of the frequency of words from "everyday life") rather than from books.

\subsection{Comparative analyses with previous normative Spanish databases}

To our knowledge, four databases of ambiguous words in Spanish have been published prior to the present one. While the first two included both homonymous and polysemous words (Estévez, 1991; Study 1 and Study 2), Nievas and Cañas' database (1993) contained only homographs, and the normative study by Domínguez et al. (2001) only polysemous words. More recently, Gómez-Veiga et al. (2010) compiled a word database which included the responses of both adults

\footnotetext{
${ }^{3}$ At qualitative level of analysis, we found some differences between dictionary and participants' senses that deserve at least a brief comment. For example, although cateto $\left(\mathrm{H}_{-}\right)$has two entries with just one sense each in the dictionary, participants not only give the "side of the triangle" meaning, but also tend to differentiate two senses within the secondary meaning: a sense concerning an "uncultured, rude person", and a sense rather concerning a "fool, dumb person". Also, some homonymous words with several senses in one (or more) of their entries in the dictionary (e. g., heroina [heroin: $\mathrm{E} 1=1$. a distinguished woman, 2. a woman who performed a feat, 3. a woman who is the main actress in a play or film; E2 = drug]) were just assigned the two unrelated "core" meanings ("brave woman" and "drug") by participants, who did not seem to distinguish the different senses provided in the dictionary for some of the entries. Obviously, sometimes the differences among senses are so subtle that, in the absence of context, people are unable to recall the nuances of each. That does not mean they cannot perceive them when those words are embedded in sentences or texts. There may also be a general imbalance between meaning production and comprehension. Moreover, unlike words in the $\mathrm{H}+$ set, some $\mathrm{H}$ - words with several senses in the dictionary were only assigned two unrelated meanings by participants. Thus, very few words seem to operate as true homonymous for participants (four words in our database). Interestingly, a number of words in the polysemous sets were given only two senses, although these were related senses.
} 
and children. Although all these datasets are based on meanings reported by participants, they differ from ours not only in the type and number of words, but also in the procedures used to select them and to estimate their final number of meanings (or senses). We will briefly describe the novel features of our database in comparison to these other ones.

With respect to Estévez (1991), this involved two studies, one with homonymous words and another with polysemous words. In the first of these, participants were asked to write down all meanings they were able to recall for 152 homonyms selected from the 1984 edition of the RAE Dictionary. In the second, participants were asked to write down as many sentences or meanings they knew for 61 polysemous words. A potential limitation of these two studies is that, after checking the meanings from participants and the dictionary, only the two most predominant meanings provided by each individual were computed. The database developed by Nievas and Cañas (1993) was created by using a free-association task with 148 homographs taken from words which are said to have two entries in the 1977 Everest dictionary. The database contained the primary and the secondary associates for each word. Since the methodology aims of Nievas and Cañas' study were not specifically focused on the creation of a normative database of homonymous words, we cannot directly compare it with our dataset. It is worth noting that many of the homographs included in both Estévez's (1991) and Nievas et al.'s (1993) databases only have one entry in the 22nd version of the RAE dictionary (2001); indeed, they have no more than one entry in the 1984 version of the dictionary (the edition used by Estévez). Therefore, many of the words selected as homonymous by these authors are actually polysemous words.

The database compiled by Domínguez et al. (2001) is based on 100 polysemous words. For each word, participants were asked to retrieve the different meanings they knew and to create three corresponding sentences. A potential limitation of this study is that on preventing participants from giving all meanings they know, some of the subordinate meanings may have been underestimated (see Gee and Harris, 2010, for discussion).

More recently, Gómez-Veiga et al. (2010) compiled a database of 113 ambiguous words in which there was no differentiation between homonymous and polysemous words. In an initial stage, the authors asked three individuals (two adults and one child) to spontaneously produce ambiguous words, although the authors did not provide details about the collection procedure. For each of these words, participants were asked to define and write down all meanings they knew in the same order as they recalled them. Our database has a number of advantages with respect to the Gómez-Veiga et al. database. First, ours has nearly twice as many words (i.e., it may be difficult to match stimuli from a database composed of around one hundred words). Second, our database includes 77 noun homographs available in Spanish, whereas the Gómez-Veiga et al. database includes only 24 homonymous words according to the 22nd edition of the RAE dictionary (i. e., it may be difficult to prepare a well-controlled experiment on the processing of homonyms with only around twenty items overall while matching for other relevant factors). Third, our database offers the senses (and meanings) from the Spanish dictionary as a function of participants' responses, whereas in Gómez-Veiga et al.'s database only the senses given by the participants are included, without a cross-validation in a dictionary.

\section{Conclusions}

The SAW database provides researchers with 210 Spanish homonymous and polysemous words (nouns) classified according to both lexicographical criteria and subjective responses collected through a meaning retrieval task. Each word is presented with its number of entries (meanings) and senses in the dictionary, together with the total number of senses provided by the participants, and the percentage of participants who responded by giving each sense in different orders. The degree of balance between the two primary meanings of the nouns is also provided, in qualitative terms. Whereas there was a moderately high relationship between the number of senses included in the dictionary and those provided by participants $(r=62)$, regression analyses on lexical decision and naming times revealed a substantial predictive power for participants' numbers of senses, but not for those of the dictionary.

Although more empirical research is needed to explore further the processing of ambiguous words in Spanish, the normative data presented here seem to reflect the psychological reality of subjective word senses. In English, this variable has been demonstrated to affect word recognition in both the visual and auditory domains (Rodd et al., 2002). Moreover, our data show that, as in English (Armstrong et al., 2012), pure homographs that only have unrelated meanings are extremely rare in Spanish.

Aside from semantic ambiguity within a language, another important area in which this dataset might be useful is bilingualism. It has been shown that when people are asked to translate an ambiguous word, they are slower and less accurate than in the case of single-translation words (e.g., Laxén and Lavaur, 2010). Moreover, ambiguous words in one language rarely correspond to a single word in another (Degani and Tokowicz, 2010). These multiple-translation words have shown a disadvantage in terms of latency and accuracy during translation when compared with one-translation words (see Boada et al., 2013). As can be inferred from the Methodology section above, many words in this database will have multiple translations not only in English, but also in other languages. Therefore, our database is a potentially useful 
tool for researchers interested in translation ambiguity, ambiguous word processing in bilinguals, or those concerned with studying how "old" meanings become associated with new words in a second language.

Finally, one of the main concerns for models of word processing is that of explaining how access to the complex net of semantic representations, either in one or more languages, is naturally achieved. In this regard, these models should be able to account for how multiple meanings and senses of an ambiguous word are learned and represented in a lexicon that is constantly evolving. The SAW database will be useful for research aimed at understanding of this complex and important issue.

\section{Appendix A. Supplementary data}

Supplementary data associated with this article can be found, in the online version, at http://dx.doi.org/10.1016/j. lingua.2016.07.002.

\section{References}

Armstrong, B.C., Tokowicz, N., Plaut, D.C., 2012. eDom: norming software and relative meaning frequencies for 544 English homonyms. Behav. Res. Methods 44 (4), 1015-1027. http://dx.doi.org/10.3758/s13428-012-0199-8

Azuma, T., 1996. Familiarity and relatedness of word meanings: Ratings for 110 homographs. Behav. Res. Methods Instrum. Comput. 28 (1), 109-124. http://dx.doi.org/10.3758/BF03203645

Azuma, T., Van Orden, G.C., 1997. Why SAFE is better than FAST: the relatedness of a word's meanings affects lexical decision times. J. Memory Lang. 36 (4), 484-504. http://dx.doi.org/10.1006/jmla.1997.2502

Boada, R., Sánchez-Casas, R., Gavilán, J.M., García-Albea, J.E., Tokowicz, N., 2013. Effect of multiple translations and cognate status on translation recognition performance of balanced bilinguals. Bilingualism: Lang. Cogn. 16, 183-197. http://dx.doi.org/10.1017/ S1366728912000223

Cuetos, F., Domínguez, A., De Vega, M., 1997. El efecto polisemia. Ahora lo ves otra vez.(The polysemy effect. Now you see it again). Cognitiva 9 (2), 175-194.

Davies, R., Barbón, A., Cuetos, F., 2013. Lexical and semantic age-of-acquisition effects on word naming in Spanish. Mem. Cogn. 41 (2), $297-$ 311. http://dx.doi.org/10.3758/s13421-012-0263-8

Degani, T., 2011. Bidirectional transfer: Consequences of translation ambiguity for bilingual word meaning (Unpublished doctoral dissertation). University of Pittsburgh, Pittsburgh..

Degani, T., Tokowicz, N., 2010. Ambiguous words are harder to learn. Bilingualism: Lang. Cogn. 13, 299-314.

Diccionario Everest, 1973. Diccionario de la lengua española, versión reducida. Everest, León, España.

Domínguez, A., Cuetos, F., De Vega, M., 2001. 100 palabras polisémicas con sus acepciones (One-hundred polysemous words with their senses). Rev. Electrón. Metodol. Apl. 6 (2), 63-84.

Duchon, A., Perea, M., Sebastián-Gallés, N., Martí, A., Carreiras, M., 2013. EsPal: one-stop shopping for Spanish word properties. Behav. Res. Methods 45 (4), 1246-1258. http://dx.doi.org/10.3758/s13428-013-0326-1

Duffy, S.A., Morris, R.K., Rayner, K., 1988. Lexical ambiguity and fixation times in reading. J. Mem. Lang. 27 (4), 429-446. http://dx.doi.org/ 10.1016/0749-596X(88)90066-6

Estévez, A., 1991. Estudio normativo sobre ambigüedad en castellano (Norming study on ambiguity in Spanish). Cognitiva 3 (2), $237-246$.

Ferrándiz, P., Peraita, H., 1985. Procesamiento de palabras ambiguas y no ambiguas empleando dos índices de activación y tiempos de reacción (Ambiguous and non-ambiguous word processing using two indices of arousal and reaction times). Estud. Psicol. 19-20, 51-61.

Frazier, L.W., Rayner, K., 1990. Taking on semantic commitments: processing multiple meanings vs. multiple senses. J. Mem. Lang. 29 (2), 181200. http://dx.doi.org/10.1016/0749-596X(90)90071-7

Gawlick-Grendell, L.A., Woltz, D.J., 1994. Meaning dominance norms for 120 homographs. Behav. Res. Methods Instrum. Comput. 26 (1), 5-25. http://dx.doi.org/10.3758/BF03204557

Gee, N.R., Harris, S.L., 2010. Homograph norms: an alternative approach to determining meaning dominance. Behav. Res. Methods 42 (4), $976-$ 986. http://dx.doi.org/10.3758/BRM.42.4.976

Geis, M.F., Winograd, E., 1974. Norms of semantic encoding variability for fifty homographs. Bull. Psychon. Soc. 3, 429-431.

Gernsbacher, M.A., 1984. Resolving 20 years of inconsistent interactions between lexical familiarity and orthography, concreteness, and polysemy. J. Exp. Psychol.: Gen. 113, 256-281.

Gómez-Veiga, I., Carriedo, N., Rucián, M., Vila, J.O., 2010. Estudio normativo de ambigüedad léxica en castellano, en niños y en adultos (Norming study on lexical ambiguity in Spanish, in children and adults). Psicologica 31, 25-47.

González-Nosti, M., Barbón, A., Rodríguez-Ferreiro, J., Cuetos, F., 2014. Effects of the psycholinguistic variables on the lexical decision task in Spanish: a study with 2,765 words. Behav. Res. Methods 46 (2), 517-525. http://dx.doi.org/10.3758/s13428-013-0383-5

Hino, Y., Lupker, S.J., 1996. Effects of polysemy in lexical decision and naming: an alternative to lexical access accounts. J. Exp. Psychol.: Hum. Percep. Perform. 22, 1331-1356.

Hino, Y., Pexman, P.M., Lupker, S.J., 2006. Ambiguity and relatedness effects in semantic tasks: are they due to semantic coding? J. Mem. Lang. 55 (2), 247-273. http://dx.doi.org/10.1016/j.jml.2006.04.001

Jastrzembski, J., 1981. Multiple meaning, number of related meanings and lexical search speed. J. Verb. Learn. Verb. Behav. 13, $278-305$.

Klepousniotou, E., 2002. The processing of lexical ambiguity: homonymy and polysemy in the mental lexicon. Brain Lang. 81 (1-3), $205-223$.

Klepousniotou, E., Baum, S.R., 2007. Disambiguating the ambiguity advantage effect in word recognition: an advantage for polysemous but not homonymous words. J. Neuroling. 20 (1), 1-24. http://dx.doi.org/10.1016/j.jneuroling.2006.02.001 
Klepousniotou, E., Pike, G.B., Steinhauer, K., Gracco, V., 2012. Not all ambiguous words are created equal: an EEG investigation of homonymy and polysemy. Brain Lang. 123 (1), 11-21. http://dx.doi.org/10.1016/j.bandl.2012.06.007

Laxén, J., Lavaur, J.M., 2010. The role of semantics in translation recognition: effects of number of translations, dominance of translations and semantic relatedness of multiple translations. Bilingualism: Lang. Cogn. 13, 157-183.

Lyons, J., 1977. Semantics, vol. 2. Cambridge University Press, Cambridge, UK.

Milberg, W., Blumstein, S.E., Dworetzky, B., 1987. Processing of lexical ambiguities in aphasia. Brain Lang. 31 (1), $138-150$.

Moldovan, C.D., Ferré, P., Demestre, J., Sánchez-Casas, R., 2014. Semantic similarity: normative ratings for 185 Spanish noun triplets. Behav. Res. Methods. http://dx.doi.org/10.3758/s13428-014-0501-z

Nelson, D.L., McEvoy, C.L., Walling, J.R., Wheeler, J.W., 1980. The University of South Florida homograph norms. Behav. Res. Methods Instrum. 12 (1), 16-37. http://dx.doi.org/10.3758/BF03208320

Nievas, F., Cañas, J.J., 1993. Asociados de una base de homógrafos (Associates for a homograph wordbase). Psicológica 14, 269-279.

Nievas, F., Justicia, F., Cañas, J.J., Bajo, M.T., 2005. Lexical processing of ambiguous words: dominance or associative strength? Spanish J. Psychol. 8 (2), 157-179.

Pexman, P.M., Lupker, S.J., 1999. Ambiguity and visual word recognition: can feedback explain both homophone and polysemy effects? Can. J. Exp. Psychol. 53 (4), 323-334.

Rabagliati, H., Snedeker, J., 2013. The truth about chickens and bats: ambiguity avoidance distinguishes types of polysemy. Psychol. Sci. 24 (7), 1354-1360. http://dx.doi.org/10.1177/0956797612472205

Real Academia Española, 2001. Diccionario de la Lengua Española, 22nd ed. España, Madrid.

Rodd, J., Gaskell, G., Marslen-Wilson, W., 2002. Making sense of semantic ambiguity: Semantic competition in lexical access. J. Mem. Lang. 46 (2), 245-266. http://dx.doi.org/10.1006/jmla.2001.2810

Rodd, J., Gaskell, G., Marslen-Wilson, W., 2004. Modelling the effects of semantic ambiguity in word recognition. Cogn. Sci. 28 (1), 89-104. http:// dx.doi.org/10.1016/j.cogsci.2003.08.002

Rubenstein, H., Garfield, L., Millikan, J., 1970. Homographic entries in the internal lexicon. J. Verb. Learn. Verb. Behav. 9, $487-494$.

Sereno, S.C., Brewer, C.C., O'Donnell, P.J., 2003. Context effects in word recognition: evidence for early interactive processing. Psychol. Sci. 14 (4), 328-333. 